\title{
Preliminary studies on hydrothermal synthesis of zeolite from Malaysian kaolinite clays
}

\author{
Tijjani Abdullahi a, c, ${ }^{\star}$, Zawati Harun a, ${ }^{\star}$, Mohd Hafiz Dzarfan Othman ${ }^{b}$, Khairul Nazri Yusof a, Ainun \\ Rahmawati ${ }^{d}$, Muhamad Zaini Yunos ${ }^{d}$, Mohd Amri Lajis ${ }^{d}$, Yusri Yusof ${ }^{d}$ \\ a Advanced Manufacturing and Material Center (AMMC), Faculty of Mechanical and Manufacturing Engineering, Universiti Tun Hussein Onn \\ Malaysia, 86400 Parit Raja, Batu Pahat, Johor, Malaysia \\ b Advanced Membrane Technology Research Centre (AMTEC), Faculty of Chemical and Energy Engineering, Universiti Teknologi Malaysia, \\ 81310 Skudai, Johor, Malaysia \\ c School of Technology Education, Federal College of Education (Technical) P.M.B. 60 Gombe, Nigeria \\ d Faculty of Mechanical and Manufacturing Engineering, Universiti Tun Hussein Onn Malaysia, 86400 Parit Raja, Batu Pahat, Johor, Malaysia
}

*Corresponding author: zawati@uthm.edu.my, abdulltj@gmail.com

\section{Article history}

Received 5 May 2018

Revised 1 June 2018

Accepted 2 July 2018

Published Online 25 June 2019

\begin{abstract}
The use of kaolin as a source of silica and alumina for synthesis of zeolite has been widely reported with various compositions and processing routes. However, since kaolin is highly influenced by geological origin and geographical formation, coupled with the processing method, two different crude kaolin were obtained at various locations in Peninsular Malaysia to serve as precursor for synthesis of zeolite. Hydrothermal treatments were made at reasonable low temperature of $90^{\circ} \mathrm{C}$ in an oven. The synthesized product was then analyzed using X-ray diffraction and scanning electron microscopy, to evaluate the potentials of the process and the product. The outcome of the analysis suggested that the breaking down of the clay structure and the armophization process can improve raw material reactivity. However, the crystallinity and composition of the crude kaolin together with appropriate incubation time can greatly influence the synthesis process and the product.
\end{abstract}

Keywords: Zeolite, hydrothermal, kaolin, synthesis, Malaysia

\section{INTRODUCTION}

It has been documented that Malaysia has about 112 million tons of kaolin reserve, 559 million tons of ball clay and 228 million tons of mottle clay. Thus, giving the total clay reserve of about 900 million tons [1]. However, with the recent additional discoveries of more kaolin deposits in Sg. Rasau, Pahang, Mersing area of Johor and the claim of good clay and feldspar rich deposits in Grik, Perak [2], it is obvious that the kaolin and other clay deposits in Malaysia is more than the stated figure. Kaolinite clay is a versatile industrial mineral as it is widely used as raw material for ceramic wares, paper, paints rubber, catalyst, dye, insecticide and in pharmaceutical.

The geological origin and geographical formation of kaolin coupled with the processing method can influence some physical and chemical properties of kaolin, which invariably affects its industrial application capabilities. Kaolin has been processed in different varieties in Malaysia for local and export consumption for many years ago. Regrettably, all the documented clay resources (kaolin inclusive) are not thoroughly studied for possible use in high value industrial product. Hence, the objective of this study was geared towards optimizing the usage of the huge kaolin resources available in Malaysia.

Zeolites are crystalline, microporous, aluminosilicate materials with a three dimensional fully cross-linked open framework structures that form a uniformly sized pores of molecular dimensions. The materials have huge industrial, scientific, and academic interest in the areas of ion exchange (treatment of liquid waste, detergent industry, and radioactive waste storage), petroleum refining along with petrochemicals, coal and fine chemical industries $[3,4]$ and separation (purification, drying, and environmental treatment). The ability of zeolites to act as multi-functional materials in many industrial applications is due to their inherent properties such as uniform pore size/shape, catalytic activity, mobile cation and hydrophilicity /hydrophobicity [5].

However, the preparation of synthetic zeolites from chemical source of silica and alumina is relatively expensive [6, 7]. Numerous studies have been conducted in searching for affordable raw materials that are suitable for synthesis of zeolite $[8,9]$. The use of kaolin as a source of silica and alumina for synthesis of zeolite has been widely reported with various compositions and processing routes [10-12]. Nonetheless, since kaolin is highly influenced by couple of factors as highlighted above, and there has been a rising need for zeolites in many aspect of developing technology as well as the enthusiasm toward developing natural resources for optimum industrial application. Many scholars [13, 14] have attempted in directly synthesizing kaolin to zeolite, but the results obtained are poor [15], with much formation of hydrosodalite. Hence, this study subjected the crude kaolin to calcination treatment (also called metakaolinization). Despite a large amount of work on metakaolinization for synthesis of zeolite [12, 13, 16], the disagreement between researchers on the appropriate condition for metakaolinization treatment makes it attractive to look into metakaolinization of Malaysian crude kaolin clay for the synthesis of zeolite. In this work, a considerable low calcination temperature was used in attaining most economical process. 


\section{EXPERIMENTAL}

\section{Materials}

Two different crude kaolin were obtained at various locations in Peninsular Malaysia as shown in figure 1. Mineralogical studies of the two kaolinite samples showed that they were differed in their elemental composition, but their $\mathrm{Si} / \mathrm{Al}$ ratio was suitable for use as a precursor for zeolite synthesis. While sodium hydroxide pellets of analytical grade were supplied by (BG Oil Chem Sdn. Bhd.) Malaysia.

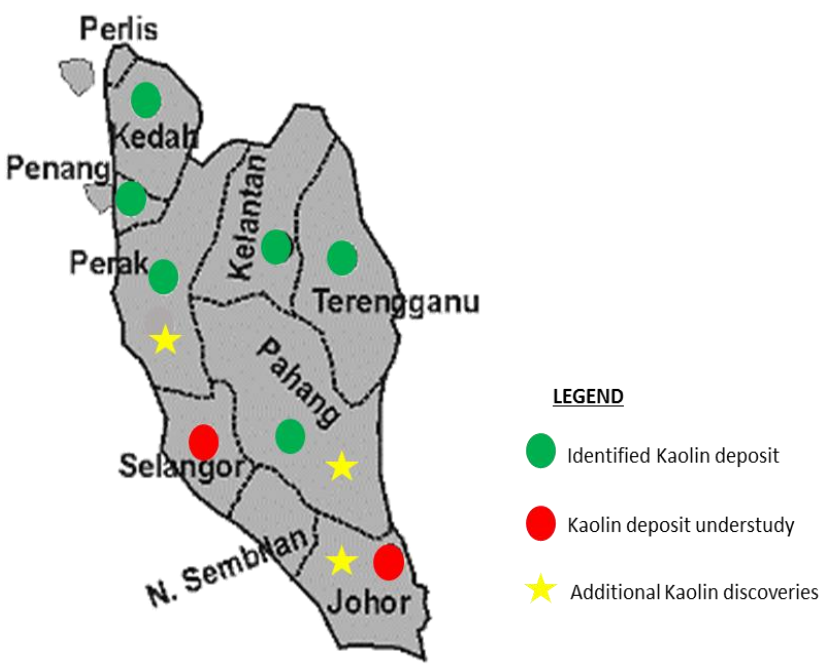

Fig. 1 Map of Peninsular Malaysia showing the location of kaolin deposits under study.

\section{Calcination of kaolin}

A portion of the crude kaolin samples was placed in open alumina crucibles and then heated in a muffle furnace to a calcination temperature of $700^{\circ} \mathrm{C}$ for $2 \mathrm{~h}$ at a heating rate of $5^{\circ} \mathrm{C} / \mathrm{s}$. Upon reaching the calcination temperature, the crucibles were allowed to cool in the furnace. At the end, the crucibles were removed from the furnace and the samples were evacuated to get a semi amorphous material with freely exchange sodium ion in its structure. The chemical composition analysis of the crude kaolin and the calcined kaolin was performed under X-ray diffractometer (XRD) and scanning electron microscope (SEM).

\section{Hydrothermal synthesis}

Three grams of metakaolin was mixed with $75 \mathrm{ml} \mathrm{NaOH}$ solution. The reaction mixture was obtained by slowly adding the metakaolin powder into the $\mathrm{NaOH}$ solution and thorough mixing. The composition of the prepared reaction mixture was based on the work of Chandrasekhar and Pramada [13]. Ageing of the reaction mixture was achieved by continuous stirring the mixture for $12 \mathrm{~h}$ at $50^{\circ} \mathrm{C}$, there was no loss of liquid because the ageing was done in a close container. The mixture was then transferred into a $100 \mathrm{ml}$ Teflon lined autoclave and the crystallization was carried out at reasonable low temperature of 90 ${ }^{\circ} \mathrm{C}$ at different time intervals of 6,9 and $12 \mathrm{~h}$. At the end of the reaction, the supernatant was collected and the product was washed using deionized water until a $\mathrm{pH}$ of 8 was achieved. After which, the solid was dried in the oven at $90^{\circ} \mathrm{C}$ for $12 \mathrm{~h}$.

\section{Characterization}

$\mathrm{X}$-ray diffraction (XRD) analysis of the crude kaolin clays and zeolitic products was accomplished using a Philips X-ray diffractometer (Model Bruker D8, Germany) which operated at $40 \mathrm{~mA}$ and $40 \mathrm{kV}$ from $10{ }^{\circ} \mathrm{C}$ and $90{ }^{\circ} \mathrm{C}$ with a step increment rate of 0.02 $\%$ min. The phase identification was conducted by searching and matching the obtained spectra with the powder diffraction file data base. Meanwhile, the composition of the crude kaolin was evaluated using X-ray Fluorescence (XRF). Scanning electron microscopy (JSM6380LA; Joel) was used for morphological analysis.

\section{RESULTS AND DISCUSSION}

\section{Evaluation of the crude kaolin}

The elemental composition of the crude kaolin clay materials was examined and the outcome was presented in Table 1. The two kaolin clays contained various percentages of exchangeable cations such as $\mathrm{Ca}, \mathrm{Mg}, \mathrm{Fe}, \mathrm{Na}$ and $\mathrm{K}$, depending on their location and geological history of the primary kaolinites. The Johor kaolin clay was observed to have a fairly higher content of $\mathrm{Fe}$ and $\mathrm{K}$, while Selangor kaolin has more $\mathrm{Mg}$ and $\mathrm{Ca}$. These cations presented in the feedstock are expected to be exchanged to other desirable cations during and after the synthesis process. The $\mathrm{Si} / \mathrm{Al}$ ratio of the starting materials was evaluated, in which Selangor kaolin has 1.2 and Johor kaolin has 1.4. Owing to the importance of having a suitable $\mathrm{Si} / \mathrm{Al}$ ratio for a better synthesis, these ratios make them as suitable starting materials for the synthesis of high value zeolites.

Table 1 Elemental composition of the crude kaolin clays.

\begin{tabular}{ccc}
\hline Constituent & $\begin{array}{c}\text { Selangor kaolin } \\
\text { weight (\%) }\end{array}$ & $\begin{array}{c}\text { Johor kaolin } \\
\text { weight (\%) }\end{array}$ \\
\hline $\mathrm{SiO}_{2}$ & 48.60 & 53.06 \\
$\mathrm{Al}_{2} \mathrm{O}_{2}$ & 39.30 & 37.36 \\
$\mathrm{TiO}_{2}$ & 0.56 & 1.27 \\
$\mathrm{Fe}_{2} \mathrm{O}_{3}$ & 0.65 & 1.80 \\
$\mathrm{MgO}$ & 0.10 & 0.05 \\
$\mathrm{CaO}$ & 0.50 & 0.28 \\
$\mathrm{~K}{ }_{2} \mathrm{O}$ & 1.50 & 2.0 \\
L.O.I (wt \%) & 8.47 & 4.1 \\
\hline
\end{tabular}

Mineralogical analysis presented in Fig. 2 showed that the crude kaolin clays have kaolinite and quartz as common minerals, which attributing to the fact that these kaolin clay minerals are formed by gradual chemical weathering of silicate bearing rocks. However, the Selangor kaolin contained quite a little amount of Muscovite. This is expected to affect the type and quality of zeolite to be synthesized.

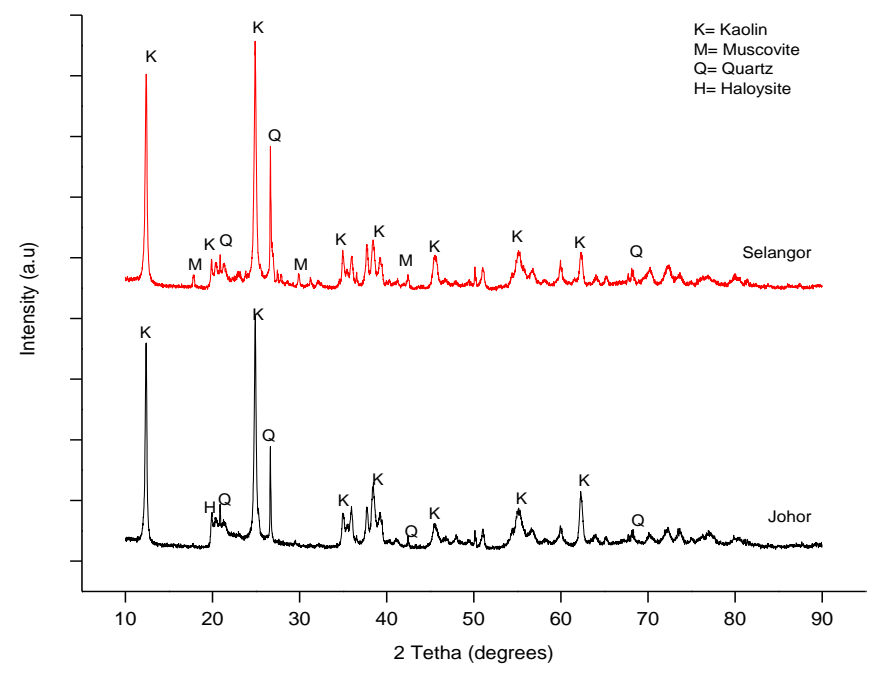

Fig. 2 X-ray diffractograms of crude kaolin samples.

The scanning electron micrographs of the crude kaolin clays in Fig. 3 showed a layered crystalline morphology, confirming the earlier study of [2,16] and the recent work of [17] on mineralogical variations of kaolin deposits in Malaysia. Further examination of the micrograph revealed that they all contained irregular platelets and-a poorly defined flakes that contained sub-rounded particles. The particle size fractions were observed to be between 2 and $10 \mu \mathrm{m}$. 

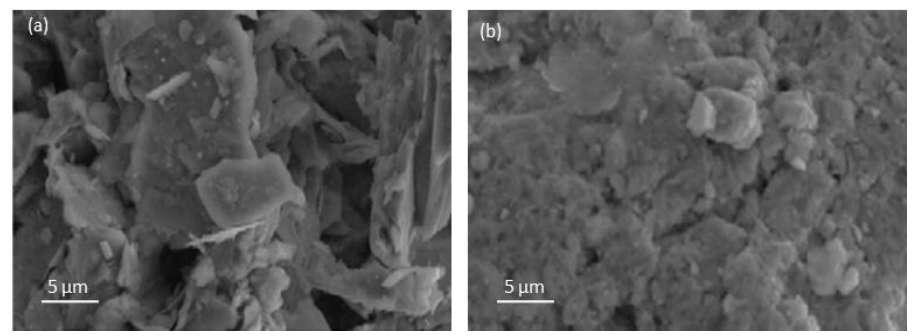

Fig. 3 SEM micrographs of the crude kaolin clays (a) Johor Kaolin and (b) Selangor kaolin.

\section{The calcination process}

From the micrograph in Fig. 4, it was clear that the calcination treatment has produced a highly disordered metakaolin that met the compositional requirement for the synthesis process. The treatment has aided the breaking down of the kaolin clay structures, forming a highly disordered and amorphous structure as it now characterized by sheetlike morphology. As earlier reported by Cundy and Chandrasekhar [15, 18], there was no consensus on the most suitable temperature for transforming kaolin to metakaolin. However, this study has achieved metakaolinization at $700^{\circ} \mathrm{C}$ for $2 \mathrm{~h}$, which conformed with the previous reports $[18,19]$. Calcination at this temperature was based on the recommendation by [20] that calcined kaolin at a medium temperature range would leave-kaolin at its lowest stability against the attack of $\mathrm{NaOH}$ and thus, producing an increased amount of $\mathrm{Al}(\mathrm{OH})_{4}$ and $\mathrm{SiO}_{4}$ species in the reaction mixture which very suitable for zeolite formation
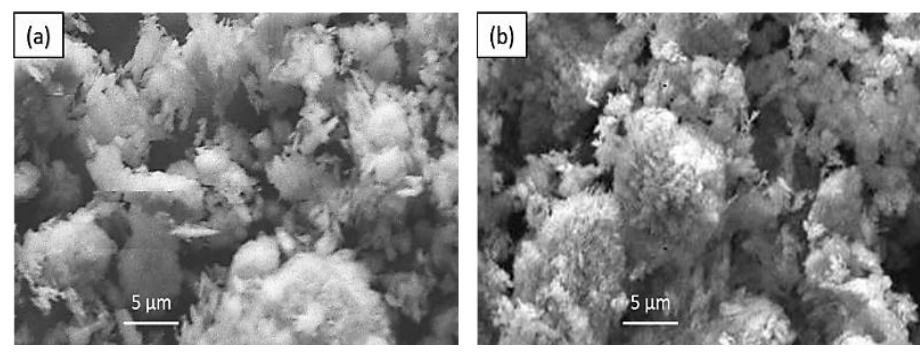

Fig. 4 SEM micrographs of the calcined kaolin clays (a) Johor Kaolin and (b) Selangor kaolin.

The XRD patterns in Fig. 5 showed amorphous and relict crystalline phases (5c) that obtained after calcination of the crude kaolin samples. Careful analysis confirmed the conversion of the kaolinite crystalline to metakaolin and thus, making it a semi amorphous material which can freely exchange sodium ion in its structure. But it has less influence on the content of quartz and haematite as rightfully observed by $[4,21]$. In addition, the comparison in chemical composition of the metakaolin and the crude kaolin samples (not shown here) showed that, the calcination induced burning of some impurities and thus, resulting in to noticeable variation of loss on ignition (LOI) value.

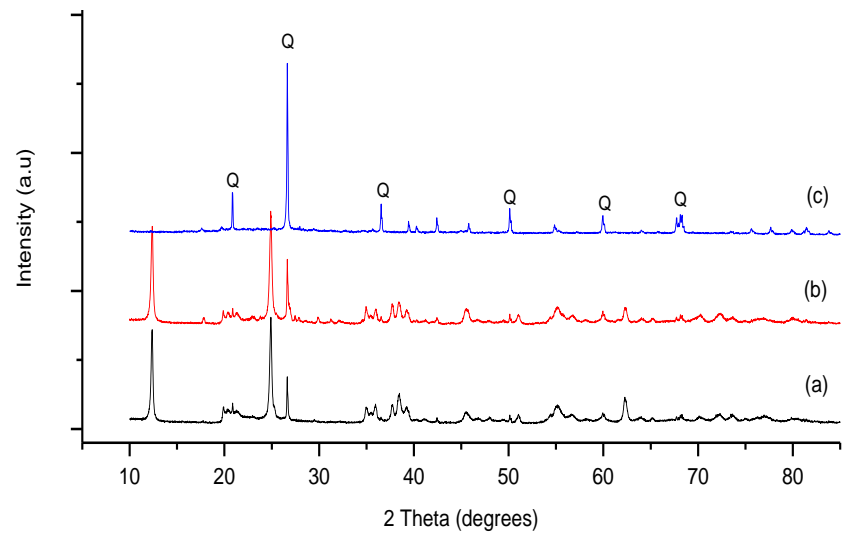

Fig. 5 X-ray patterns of (a) Johor and (b) Selangor crude kaolin samples before calcination (c) calcined kaolin.

\section{Synthesis of zeolite}

The metakaolin prepared by the calcination process was utilized for the zeolite synthesis, which was carried out at different time intervals. Fig. 6 shows the powder X-ray diffraction patterns of the crude Johor kaolin and the synthesized zeolites at different incubation times from 6 to $12 \mathrm{~h}$. However, the purity and grade of the synthesized products varied accordingly. At $6 \mathrm{~h}$ of crystallization time, zeolite 4A ICDD card: 043-0142 matched the synthesized product, while zeolite A (Na) ICDD card: 039-0222 was obtained at $9 \mathrm{~h}$ of crystallization. In a similar trend, when the crystallization time reached $12 \mathrm{~h}$, the obtained product matched a dehydrated LTA (Linde type A) ICDD card: 039-0223 zeolite. These results conformed to the report of Kugbe, et al. [22] and the collection of simulated XRD powder patterns of zeolites [23].

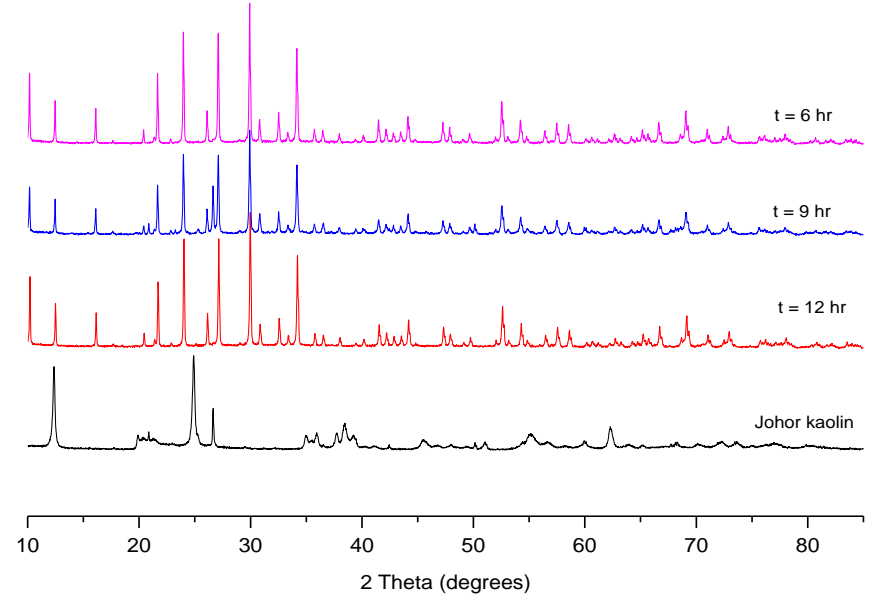

Fig. 6 X-ray diffractograms of crude Johor kaolin and the synthesized zeolites at different crystallization times.
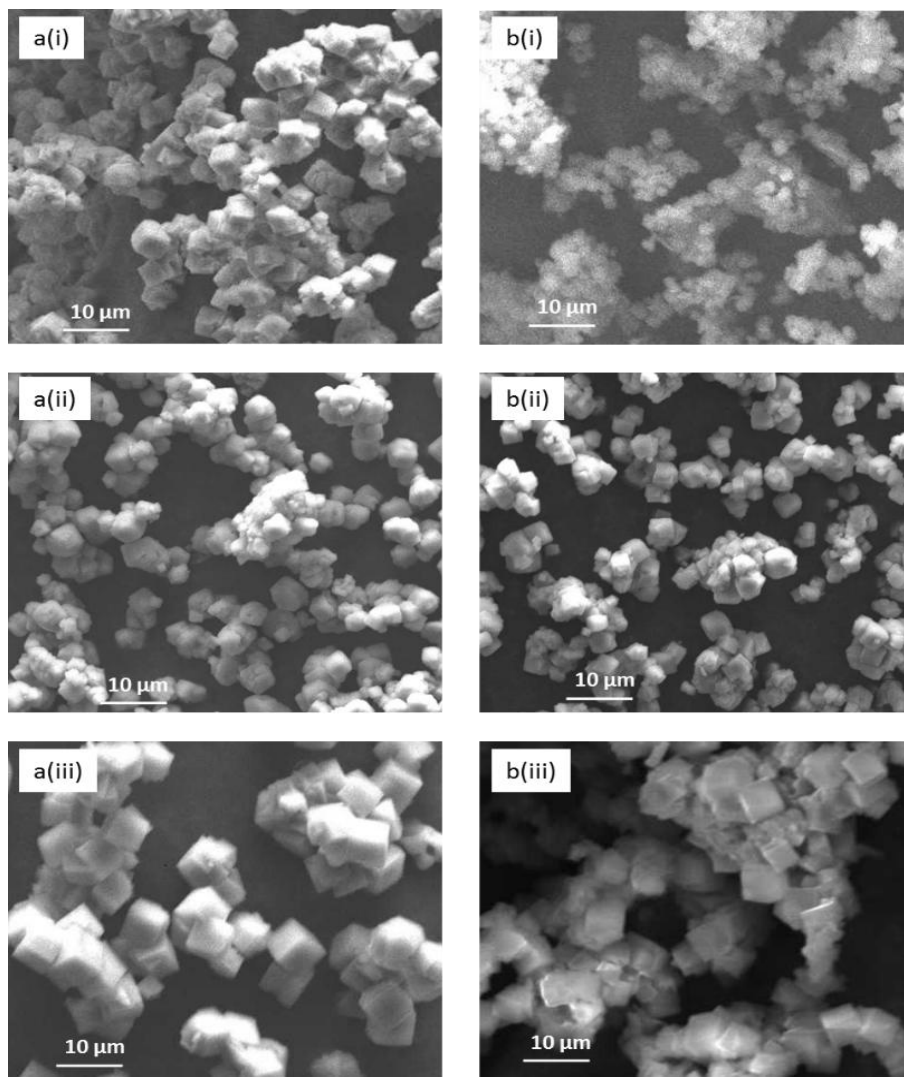

Fig. 7 SEM images of zeolites synthesized under different crystallization times, using the two different kaolin precursors (a) Johor kaolin and (b) Selangor kaolin. While, $a(i) \& b(i), a(i i) \& b$ (ii) and $a$ (iii) \& $b$ (iii) shows the results at $6 \mathrm{~h}, 9 \mathrm{~h}$ and $12 \mathrm{~h}$ respectively.

The SEM image of the crystallized products as presented in Fig. 7, further illustrated the variable kind of zeolites obtained according to the 
different kaolin compositions and the crystallization conditions (time and temperature). Fig. 7 a(i), a(ii) and a(iii) represent zeolite 4A ICDD card: 043-0142, zeolite A (Na) ICDD card: 039-0222 and dehydrated LTA (Linde type A) ICDD card: 039-0223 respectively.

By using the metakaolin processed from Selangor kaolin for the synthesis process at $6 \mathrm{~h}$, sodium aluminosilicate and quartz were the major elements presented. It is right therefore to say that no zeolite formation was noticed after $6 \mathrm{~h}$ crystallization time. The data indicated that although a significant modification took place during the crystallization after $6 \mathrm{~h}$, the structure of the sample did not transform to zeolite, instead it polymerized to form amorphous aluminosilicate with virgin nuclei which might directly transform to zeolite under a favorable incubation condition as shown in Fig. 8.

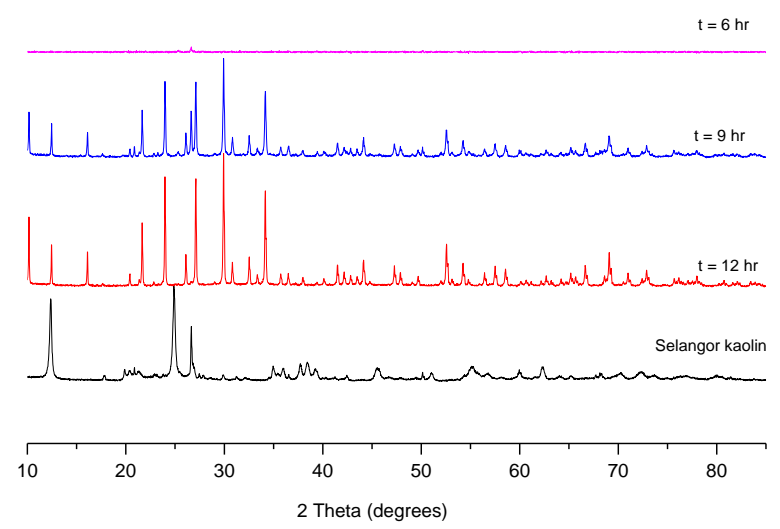

Fig. 8 X-ray diffractograms of crude Selangor kaolin and the synthesized zeolites at different crystallization times.

Prolonging the crystallization time to $9 \mathrm{~h}$ produced zeolite A (Na) which was compared well with ICDD card: 039-0222. Further increase in time of crystallization to $12 \mathrm{~h}$ produced a dehydrated LTA ICDD: 039-0223, which was similar to the product synthesized using Johor calcined kaolin as shown in Fig. 7b(i), b(ii) and b(iii) (aluminosilicate, zeolite $\mathrm{A},(\mathrm{Na})$ and dehydrated LTA).

The effect of different the synthesis times resulted in producing different zeolite types. This phenomenon occurs as a result of the fact that zeolites are thermodynamically metastable phases, in such a way that the Ostwald's law of successive reactions overwhelmed the synthesis process. Considering the results obtained in this study, the metastable (aluminosilicate) phase appeared at $6 \mathrm{~h}$ crystallization time. However, by prolonging the time of synthesis to $9 \mathrm{~h}$, a more stable phase (zeolite $\mathrm{A},(\mathrm{Na})$ ) replaced the former.

The percentage yield of the dried synthesized zeolite powder was calculated in respect to the obtained product yield verses the theoretical yield which was computed from the synthesis reaction equation as shown below:

$$
\mathrm{Al}_{2} \mathrm{O}_{3}-2 \mathrm{SiO}_{2}+2 \mathrm{NaOH} \rightarrow \mathrm{Na}_{2} \mathrm{O}-\mathrm{Al}_{2} \mathrm{O}_{3}-2 \mathrm{SiO}_{2}-4.5 \mathrm{H}_{2} \mathrm{O} .
$$

Table 2 describes in detail the percentage yield of the synthesized zeolite using both the Johor and Selangor calcined kaolin. It can be seen that all the two kaolin samples have yeilded fairly good at $9 \mathrm{~h}$ and $12 \mathrm{~h}$ crystallization times. Contrary to this, the selangor kaolinite failed to produce the expected zeolite at $6 \mathrm{~h}$ crystallization period and the reason for this failure has been discussed in the previous section. Nontheless, the Johor kaolinite has demonstrated to be more suitable in yeilding more product than the other, this is crucial when commercialization or large scale production is considered.

Table 2 Yield percent of the zeolite product synthesized from the two sampled kaolin.

\begin{tabular}{|c|c|c|c|}
\hline \multirow{2}{*}{ Kaolin } & \multicolumn{3}{|c|}{$\%$ Yield } \\
\hline & $6 \mathrm{~h}$ & $9 \mathrm{~h}$ & $12 \mathrm{~h}$ \\
\hline Johor & 71 & 78 & 82 \\
\hline Selangor & 0 & 69 & 80 \\
\hline
\end{tabular}

Comparison of the products synthesized from the two different crude kaolin showed that both kaolin clays are suitable as precursor for synthesis of zeolite. This study confirmed the earlier assertion that zeolites are thermodynamically metastable phases, this is because of the replacement of phases that occurred at various crystallization times.

The higher Si/Al ratio of the Selangor kaolin significantly affected the formation of zeolite, especially at $6 \mathrm{~h}$ crystallization time, due to the fact that the more $\mathrm{Al}$ content will accelerate the geopolmerization process, while the low crystallization time of the hydrothermal process is unable to create the required cations that permit zeolite formation. Therefore, the low crystallization time of the hydrothermal process combined with the differences in compositions of the crude kaolin greatly contributed to this failure.

\section{CONCLUSION}

The mineralogical studies of the two kaolinite samples showed that they are different in their elemental composition, but their $\mathrm{Si} / \mathrm{Al}$ ratio is suitable for use as a precursor for zeolite synthesis. Calcining the crude kaolin at a medium temperature prior to the synthesis operation induced the breaking down of the clay structure, thereby improving the raw material reactivity. There was replacement of phases occurred at varying crystallization time during the synthesis, this confirmed the metastable nature of zeolite. Therefore, it is highly recommended to further study the influence of temperature in relation to the alkaline concentration of the hydrothermal solution.

\section{ACKNOWLEDGEMENT}

The authors would like to acknowledge Universiti Tun Hussein Onn Malaysia, Centre for Graduate Studies, ORICC for the Graduate Research Incentive Grant (Vot No: U738), TRGS Vot T001 for partly sponsoring this paper and Tertiary Education Trust Fund (TETFUNDNigeria) Federal College of Education (Technical) Gombe, Nigeria.

\section{REFERENCES}

[1] M. Malaysia, "Malaysian Minerals Yearbook 2012," Minerals and Geoscience Department Malaysia, 2012.

[2] K. S. Ariffin, H. A. Rahman, H. Hussin, and K. A. A. Hadi, "The genesis and characteristics of primary kaolinitic clay occurrence at Bukit Lampas, Simpang Pulai, Ipoh," Bulletin of the Geological Society of Malaysia, vol. 54, 2008.

[3] A. Chiang and K.-j. Chao, "Membranes and films of zeolite and zeolitelike materials," Journal of Physics and Chemistry of Solids, vol. 62, pp. 1899-1910, 2001.

[4] T. Abdullahi, Z. Harun, and M. H. D. Othman, "A review on sustainable synthesis of zeolite from kaolinite resources via hydrothermal process," Advanced Powder Technology, 2017.

[5] M. Gougazeh and J.-C. Buhl, "Synthesis and characterization of zeolite A by hydrothermal transformation of natural Jordanian kaolin," Journal of the Association of Arab Universities for Basic and Applied Sciences, vol. 15, pp. 35-42, 2014.

[6] L. McCusker, F. Liebau, and G. Engelhardt, "Nomenclature of structural and compositional characteristics of ordered microporous and mesoporous materials with inorganic hosts (IUPAC Recommendations 2001)," Pure and Applied Chemistry, vol. 73, pp. 381-394, 2001.

[7] E. Johnson and S. E. Arshad, "Hydrothermally synthesized zeolites based on kaolinite: A review," Applied Clay Science, vol. 97, pp. 215-221, 2014.

[8] J. Lee, S. Han, and T. Hyeon, "Synthesis of new nanoporous carbon materials using nanostructured silica materials as templates," Journal of Materials Chemistry, vol. 14, pp. 478-486, 2004.

[9] O. M. Yaghi, M. O'Keeffe, N. W. Ockwig, H. K. Chae, M. Eddaoudi, and J. Kim, "Reticular synthesis and the design of new materials," Nature, vol. 423, pp. 705-714, 2003.

[10] D. Georgiev, B. Bogdanov, Y. Hristov, and I. Markovska, "Synthesis of NaA zeolite from natural kaolinite," Oxidation Communications, vol. 34, pp. 812-819, 2011.

[11] E. A. Hildebrando, C. G. B. Andrade, C. A. F. d. Rocha Junior, R. S Angélica, F. R. Valenzuela-Diaz, and R. d. F. Neves, "Synthesis and characterization of zeolite $\mathrm{NaP}$ using kaolin waste as a source of silicon and aluminum," Materials Research, vol. 17, pp. 174-179, 2014.

[12] S. M. Holmes, S. H. Khoo, and A. S. Kovo, "The direct conversion of impure natural kaolin into pure zeolite catalysts," Green Chemistry, vol. 13, pp. 1152-1154, 2011 
[13] S. Chandrasekhar and P. Pramada, "Investigation on the synthesis of zeolite NaX from Kerala kaolin," Journal of Porous Materials, vol. 6, pp. 283-297, 1999.

[14] F. G. Colina and J. Llorens, "Study of the dissolution of dealuminated kaolin in sodium-potassium hydroxide during the gel formation step in zeolite X synthesis," Microporous and Mesoporous Materials, vol. 100, pp. 302-311, 2007.

[15] C. S. Cundy and P. A. Cox, "The hydrothermal synthesis of zeolites: history and development from the earliest days to the present time," Chemical Reviews, vol. 103, pp. 663-702, 2003.

[16] C. Belviso, F. Cavalcante, A. Lettino, and S. Fiore, "A and X-type zeolites synthesised from kaolinite at low temperature," Applied Clay Science, vol. 80, pp. 162-168, 2013.

[17] H. Baioumy, "Mineralogical variations among the kaolin deposits in Malaysia," presented at the Annual International Conference on Geological and Earth Science, 2012.

[18] S. Chandrasekhar, "Influence of metakaolinization temperature on the formation of zeolite 4A from kaolin," Clay Minerals, vol. 31, pp. 253-261, 1996.

[19] H. Feng, C. Li, and H. Shan, "Effect of calcination temperature of kaolin microspheres on the in situ synthesis of ZSM-5," Catalysis Letters, vol. 129, pp. 71-78, 2009.

[20] A. Madani, A. Aznar, J. Sanz, and J. Serratosa, "Silicon-29 and aluminum27 NMR study of zeolite formation from alkali-leached kaolinites: influence of thermal preactivation," Journal of Physical Chemistry, vol. 94, pp. 760-765, 1990.

[21] A. Elimbi, H. Tchakoute, and D. Njopwouo, "Effects of calcination temperature of kaolinite clays on the properties of geopolymer cements," Construction and Building Materials, vol. 25, pp. 2805-2812, 2011.

[22] J. Kugbe, N. Matsue, and T. Henmi, "Synthesis of Linde type A zeolitegoethite nanocomposite as an adsorbent for cationic and anionic pollutants," Journal of Hazardous Materials, vol. 164, pp. 929-935, 2009

[23] M. M. Treacy and J. B. Higgins, Collection of simulated XRD powder patterns for zeolites fifth (5th) Revised Edition: Elsevier, 2007. 